\title{
The Development of Peer Coaching Skills in Primary School Children: An Exploration of How Children Respond to Feedback
}

\author{
Linda Dorrington and Christian van Nieuwerburgh
}

\begin{abstract}
This paper reviews the development of peer coaching in primary schools with a focus on how children respond to feedback. Research shows that feedback can play a powerful part in children's learning but it is less clear why some children respond well to feedback whilst others may not. The objective of this research was to explore how primary school children respond to feedback and what influences their decisions to act on feedback received. Thematic Analysis is used to explore how 28 primary school children (10-11 year-olds) responded to feedback following a peer coaching activity. Findings suggest that a positive response to feedback was associated with: feeling valued and building on strengths; verbal feedback being preferable to written feedback; specific feedback being most helpful with; and being able to understand the feedback provided.
\end{abstract}

Index Terms - Coaching, feedback, primary schools, children, thematic analysis.

\section{INTRODUCTION}

Research shows that feedback can play a powerful part in children's learning [1] but what is less clear is why some children respond well to feedback whilst others may not. This research builds on previous research by Briggs and van Nieuwerburgh [2] who found that the quality of feedback did not seem to influence children's uptake of the suggestions made. Briggs and van Nieuwerburgh questioned 'whether attitudes towards receiving feedback' may have more of a correlation than the quality of the feedback itself. In this research, contrary to the findings of Briggs and van Nieuwerburgh, the majority of children did accept and act upon the feedback provided.

\section{LITERATURE REVIEW}

\section{A. Coaching and Feedback}

Although coaching has become increasingly popular in secondary schools for staff and student development, [3]-[5] it is still comparatively rare in primary schools (especially peer to peer coaching) because young children are perceived as lacking the maturity to deal with coaching activities. This research provides an opportunity to further develop this area. Some of the main skills of coaching are: listening, asking open questions, clarifying and encouraging reflection. Giving and receiving feedback is generally agreed to be one of the key elements related to encouraging reflection [6], [7].

Manuscript received November 10, 2013; revised January 22, 2014.

Linda Dorrington is with the University of East London, United Kingdom (e-mail: lcdorrington@gmail.com).
Effective coaches reinforce positive beliefs and provide challenge to limiting beliefs. Feedback is considered to be a fundamental part of this task [8].

\section{B. What Makes Coaching Successful?}

One of the most consistently identifiable factors seen as contributing to the success of coaching is the 'quality of the relationship between the coach and individual client' [9]-[11]. Motivation to learn was identified as one of the most critical factors influencing learning effectiveness by [12]. This point to the complex relationship between the coach and the coachee and the inter-relationship between trust, rapport, commitment and motivation in determining how effective coaching is. It is important for us to consider these in exploring how children respond to feedback.

\section{Coaching in Education}

Coaching in education has gained considerable momentum over the past 10 years. To date, however, it has been focused more within secondary or further education, being used for staff development/performance, time management, student attainment and reducing anxiety [13]-[15]. Coaching has shown "significant increases in levels of cognitive hardiness and hope" in students [16]; enhancing students' emotional intelligence; increasing their mental toughness; improving students' attitudes and hope for the future [17]. Coaching has a beneficial impact however, not only on those being coached, but on the coaches. Secondary school students trained as coaches reported increased emotional intelligence [18] as well as improved communication skills and more positive attitudes to learning.

\section{Coaching in Primary Schools}

Coaching in primary schools, comparatively rare until recently, is now gaining momentum although still focused on staff development. There is a lack of research in the use of coaching with pupils but what has been done shows value, in particular the use of feedback which suggests that more research into this area may be of real importance in raising attainment and increasing motivation in schools.

Research carried out by Madden, Green, and Grant (2011) found that the use of solution focused coaching helped primary school children in identifying their own strengths and resources with significant improvements in enhancing engagement in learning as well as their sense of hope and wellbeing [19]. This links with and supports the importance of motivation as a key factor in learning and engaging with coaching which is identified as one of the most critical factors influencing learning effectiveness. Vlach and Carver (2008) revealed that children who received observation coaching had significantly greater improvements in drawing scores 
than children who did not receive coaching [20].

\section{E. Feedback}

The generic stages of coaching consist of contracting, relationship building, assessment, feedback and reflection, goal setting and implementation [21]. Feedback is considered to be a fundamental part of this task. Hattie (2009) suggests feedback is one of the most significant factors in determining what impacts on learning, with the potential for a profound effect. However, not all feedback is effective [22]. Feedback needs to be timely; address the current task; specify next steps and how to get here; provide accurate feedback and be given in an atmosphere of trust [23]. Questions such as 'where am I going?' and 'how do I get there?' and 'where to next?' were found to have powerful effects on learning.

In his research on 'visible learning' Hattie (2009) suggested that teachers need to provide direction and re-direction to ensure that content is understood, thereby maximizing the power of feedback as well as a commitment to further challenge. This is of particular importance when considering the effectiveness of peer coaching in the classroom.

\section{F. Peer Feedback}

Whilst there is much support for the use of feedback to support training and raise attainment, there are conflicting views on the use of peer feedback. Bergen et al. (2000) support the use of peer feedback as 'collaborative and supportive, leading to professional development' [24]. Nuthall (2007) however, questions how accurate this support actually is, especially in relation to children, suggesting that $80 \%$ of feedback received in a given day is from another student and $80 \%$ of this is wrong, which is a strong indicator of the need to improve the accuracy of peer feedback [25]. He highlights the need to ensure that students have the necessary background knowledge to understand the learning tasks and the need to be actively engaged with the information. Another question which may cause some discomfort is that of challenge and whether peers (especially children) feel able/comfortable challenging each other [26].

Critics of peer feedback Connor and Asenavage (1994) suggest it is less effective than teacher feedback on students' writing as they may not take it as seriously [27]. There is also the concern about the quality of peer feedback, as some students lack the ability to give peer feedback owing to insufficient knowledge. This could be challenged by the method used in Peer-Mediated Instruction (PMI)-an approach in special education where peers of the target students are trained to provide necessary tutoring [28]. The teacher provides on-going feedback, watching the peer at all times while the intervention is being used.

In replicating the tasks used in the research carried out by Briggs and Nieuwerburgh (2010), this research aims to extend the knowledge of what makes children engage with and respond to feedback.

\section{METHODS}

The initial decision was made to use qualitative rather than quantitative research methods on the grounds that the aim was to understand the thinking process of children. A qualitative approach would allow the researchers to focus on depth and texture, trying to understand the participants' experiences and how they engage with feedback.

\section{A. Thematic Analysis (TA)}

Thematic Analysis was chosen on the basis that it provides a flexible research tool with the potential to collect rich, detailed data. It is a method for identifying, analyzing and reporting patterns (themes) within data. It allowed the researchers to organize and describe data in considerable detail and to interpret various aspects of the research topic [29].

\section{B. Stages of Research}

The participants were a mixed group of 28 primary school children (ages 10-11) who worked in friendship pairs for the feedback tasks. The children were mostly of Bangladeshi origin at a school in East London, UK.

- Consent forms were obtained from parents and school prior to the research.

- Workshop for children in class on peer coaching/feedback

- Draw a giraffe Feedback -Reflection

- Play naughts and crosses Feedback -Reflection

- Throwing and catching a ball Feedback-Reflection

- Draw a giraffe again, thinking of the feedback received earlier.

- Drawings were analysed by the researchers to determine who had taken up feedback.

- Whole class discussion

- Focus Group

- Semi-structured interviews exploring responses to feedback

- Analysis of data using Thematic Analysis

\section{Ethical Considerations}

As this research was conducted with children, parents were fully informed and consent was obtained prior to any interviews. All children had the right to withdraw from any activity if they wished at any time. All drawings and interviews were anonymous and none of the participants can be identified.

\section{REsults}

The research question was broad with no pre-conceptions or expectations, exploring children's attitudes towards feedback. The themes emerging from the data were children's experiences, shared with the researcher, therefore essentially constructing knowledge together, with the researcher having an active part in the research process. The following themes (See Table I) are what emerged from the data.

\section{DISCUSSION}

This study focused on attitudes to feedback following on from tasks carried out during the study and also children's experience of feedback in general as it was not a new concept for them. The school already uses a coaching approach which includes peer feedback and whilst still at an early stage this 
meant that the children needed little elaboration on how to use feedback.

Contrary to the findings of Briggs and van Nieuwerburgh (2010) in this study the majority of children gave specific feedback which the recipients acted upon. Reasons for this might be attributed to the following: children were familiar with the concepts of peer feedback as it is becoming common practice in the school; children were paired in chosen friendship groups so were comfortable with each other; they gave each other written feedback and discussed it, thereby reinforcing the written with verbal feedback, allowing for clarification.

TABLE I: THEMES AND QUOTES

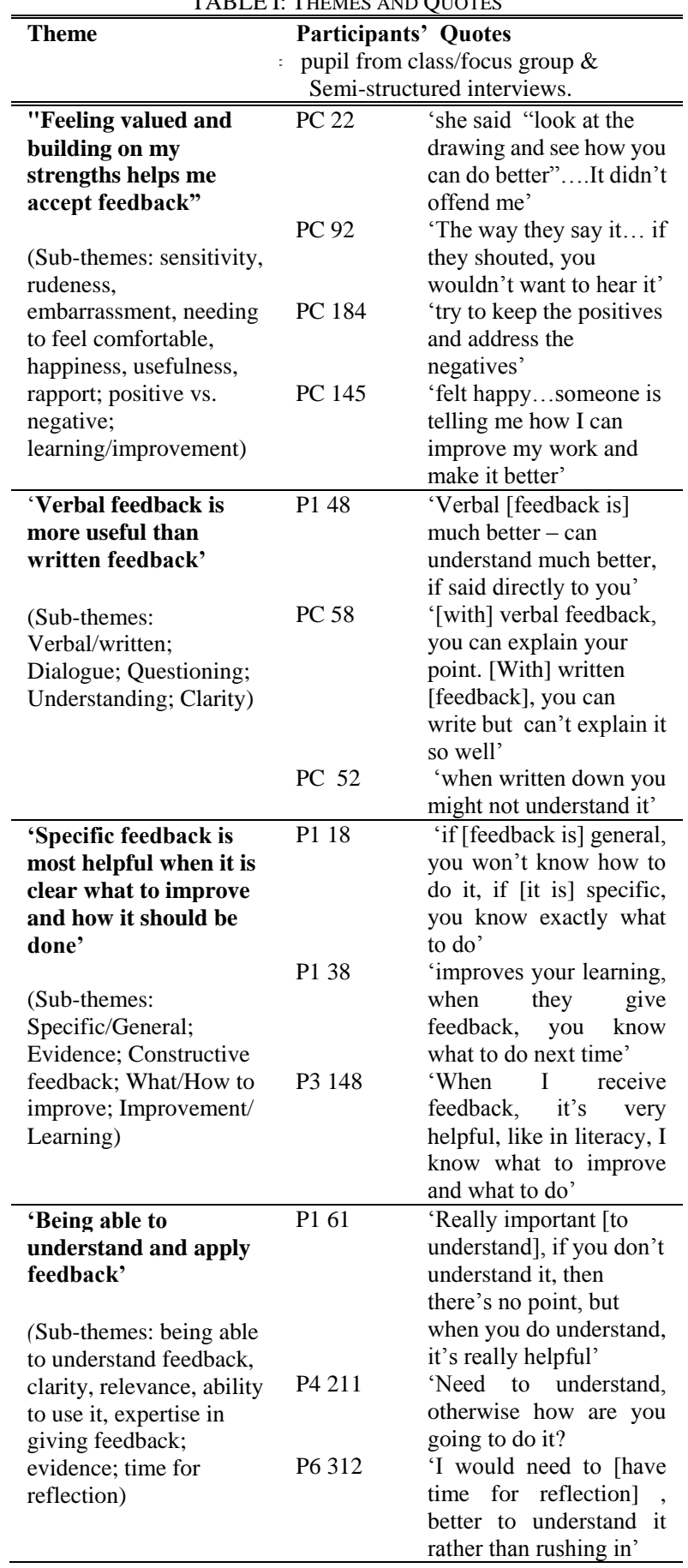

In exploring the question of how children respond to feedback and what motivates them to accept it, four main themes emerged which were found to support much of the previous research findings. There is a clear relationship between the themes with references to 'understanding', 'improvement', 'learning',[30], [31].The themes were as follows:

\section{A. "Feeling Valued and Building on My Strengths Helps Me Accept Feedback"}

Children have strong feelings about needing to feel comfortable with the person giving feedback, with references to sensitivity and feelings. 'If you don't know them, and you don't feel so comfortable with them, you might not want to take it on board' (P1). Rudeness is perceived as unhelpful leading to self-consciousness, embarrassment and affecting learning 'if they say it in a rude way, I would feel upset, it will affect my learning and make me feel self-conscious'(P2). References to the relationship with the person giving feedback 'it will build up your feelings with the other person, how you get on with them' $(P 1)$ indicates the need for trust and rapport. Children are more likely to accept feedback when the focus is on positives elements- building on strengths before addressing weaknesses. 'Better with positive points first, then the bit they don't like' (P5).

Previous research stresses the importance of the quality of the relationship, trust and rapport between the coach and coachee as positive indicators of successful outcomes which is supported by the above findings. Focusing firstly on their strengths supports research by Madden, Green and Grant (2011) who found solution focused coaching helped to enhance learning and a sense of hope and well-being. Many references in this study to 'improvement' and 'learning' supports Caley \& Mason's (2002) research on motivation as one of the most critical factors influencing learning effectiveness.

\section{B. 'Verbal Feedback is More Useful than Written Feedback'}

Children find verbal feedback more useful than written feedback, when given sensitively and discretely with clear techniques for improvement. Many references to 'understanding' and verbal feedback suggest children find it helpful to improve their work. Written feedback is considered less easy to understand but gives time for reflection which is important for future use of feedback. 'Verbal feedback ... when they say you can understand more, verbal they give examples and can clarify and you understand' (P2).

Overall, it appears that for optimum learning children like to receive both verbal and written feedback. 'Both verbal and written best - verbal you can talk about it but written you can think about it afterwards' (P6).

Research by Crews \& Wilkinson (2010) on students' perceived preference for visual and auditory feedback found that feedback which was visual, auditory, and e-handwritten helped them understand the types of errors they were making and why these errors were incorrect [32]. They also indicated this type of assessment 'would help build a relationship with the instructor and help them be successful in the class'.

\section{C. 'Specific Feedback is Most Helpful When It is Clear What to Improve and How It Should be Done'}

Children respond better to feedback which is specific and constructive with clear indicators on 'what to improve', next steps and 'how to get there'. Children's perceptions were that specific feedback leads to a higher level of understanding and 
improvements in learning. Specific feedback indicates what should be improved and techniques given as to how to improve it. 'If you get general feedback, you won't know exactly what to do' $(P C)$. Constructive feedback is seen as leading to greater learning, building on strengths, what they are already doing well before focusing on what they should improve. These findings supports the research by Hattie (2009) with questions such as 'where am I going?' and 'how do I get there?' and 'where to next?' which has important implications for the use of peer feedback and the need for guidance by the teacher on how they should give feedback to each other.

\section{D. 'Being Able to Understand and Apply Feedback'}

Children's perceptions of feedback and what influences them in taking it on board appears to be determined by several aspects. Children need to be able to understand feedback before they can use it 'If I don't understand it I wouldn't take it on board, because I might take it the wrong way and that might affect it even more'(P5). Appropriate feedback is linked to how experienced the person is: 'teachers are more experienced. Mr P has experience in writing so gives helpful feedback'(P2). Reflection on feedback and opportunities to put it into practice is considered important: 'I used to read (feedback) and carry on now I read it and then Mr P gives us time to write back (P5).

Guidance on peer feedback is considered essential for it to be effective 'We use a toolkit on the whiteboard, that's how we give feedback' (P3). This supports the need for teachers to provide direction and re-direction to ensure that content is understood as suggested by Hattie (2009). It further addresses the concerns about peer feedback by Nuthall and Connor and Asenavage who question the effectiveness of peer feedback in terms of quality and peer bias. The use of guidance (toolkit) suggests that when they are given appropriate direction peer feedback is perceived as useful.

\section{CONCLUSION}

Overall, children perceived feedback as helpful and linked to learning and improvement, with the majority of children accepting and acting on the feedback. Perceptions and uptake of feedback, however, are strongly influenced by the relationship they have with the person giving feedback; how sensitively the feedback is delivered and when the focus is on strengths. Children respond better to feedback when it is specific, emphasizing 'what' to do and 'how' to do it and when it is given verbally rather than in writing. Being able to understand feedback is important as well as reflection time to absorb and consider the feedback for future use. Peer feedback is perceived as useful and supportive but guidance on how to give it is essential.

The above findings suggest that training children in the use of feedback may result in increased motivation and greater understanding. It reveals the potential for feedback as an intervention in raising performance as well as raising the question of whether coaching and feedback can be used to address other non-academic areas such as behaviour or stress management. This research adds value to what is already known about coaching and feedback so that teachers can have a better understanding of what influences children in their uptake of feedback. Having completed this research on how children respond to feedback, we felt that there was a strong interrelationship between trust, rapport, clarity, understanding, reflection and guidance which children may need in order for feedback to be effective.

\section{A. Limitations \& Future Research}

Potential shortcomings of this study include reliability and the possibility of mis-interpreting responses. These however were clarified and questions repeated to all participants with similar responses. A high number of codes meant overlapping themes, but it was felt that there was sufficient evidence for them to stand alone as themes. The researcher worked at the school so may have had some influence on the responses received. However, as coaching was not a new concept for the children, they appeared to have quite definite views on feedback.

The findings relate to only one school and therefore should not be generalised, so it may be useful to undertake further research into this area, considering whether "children's response to feedback" is influenced by cultural or socio-economic factors. Research by Allaei and Connor, (1990) suggests that children' views of peer feedback can be very different due to cultural differences [33]. Conducting this study on a larger scale across a wider geographical area in the UK and internationally; across different socio-economic areas and different cultures as well as schools where feedback is not common practice would be useful for further research.

\section{REFERENCES}

[1] S. Hattie, Visible Learning: A Synthesis of over 800 Meta-Analyses Relating to Achievement, New York, Routledge, pp.38, 2009.

[2] M. Briggs, J. Mary, and N. C. Van, The Development of Peer Coaching Skills in Primary School Children in Years 5 and 6, 2010.

[3] S. Palmer and K. Gyllensten, "How cognitive behavioural, rational emotive behavioural or multimodal coaching could prevent mental health problems, enhance performance and reduce work related stress," The Journal of Rational Emotive and Cognitive Behavioural Therapy, vol. 26, no. 1, pp. 38-52, 2008.

[4] J. Cornett and J. Knight, "Research on coaching," in J. Knight (Ed.), Coaching: Approaches and perspectives, Thousand Oaks, CA: Sage, pp. 192-216, 2008.

[5] L. Shidler, "The impact of time spent coaching for teacher efficacy on student achievement," Early Childhood Educational Journal, vol. 36, no. 5, pp. 453-460, 2008.

[6] J. Passmore, Workplace coaching, Unpublished $\mathrm{PhD}$ thesis, University of East London, P7, 2008.

[7] P. Hawkins and N. Smith, Coaching, mentoring and organizational consultancy: Supervision and development, Maidenhead: Open University, 2006.

[8] NHS Review: Coaching Effectiveness-A Summary of a Reportfor the NHS Leadership Centre, Dr Sandra Fielden of Centre for Diversity and Work Psychology, Manchester Business School, University of Manchester.

[9] E. D. Haan, "I struggle and emerge - Critical moments of experienced coaches," Consulting Psychology Journal: Practice and Research, vol. 60 , no. 1 , pp. $106-131,2008$ b.

[10] E. C. Thach, "The impact of executive coaching and 360 feedback on leadership effectiveness," Leadership and Organization Development Journal, vol. 23, no. 4, pp. 205-214, 2002.

[11] M. E. Dingman, The Effects of Executive Coaching on Job-Related Attitudes, Regent University, 2004.

[12] L. Caley, J. Reynolds, and R. Mason, "How do people learn?" Research Report, London: CIPD, 2002.

[13] S. Allison and M. Harbour, The Coaching Toolkit: A Practical Guide for Your School, London: Sage, 2009.

[14] J. Passmore and A. Brown, "Coaching non-adult students for enhanced examination performance: a longitudinal study," Coaching: An 
International Journal of Theory, Research and Practice, vol. 2, no. 1 pp. 54-64, 2009.

[15] A. Morse, Cultivating a Math Coaching Practice: A Guide for K-8Math Educators, California: Corwin Press, 2009.

[16] S. Green, A. Grant, and J. Rynsaardt, "Evidence-based life coaching for senior high school students: Building hardiness and hope," International Coaching Psychology Review, vol. 2, no. 1, pp. 24-32, 2007.

[17] C. van Nieuwerburgh and C. Tong, "Exploring the benefits of being a student coach in educational settings: a mixed-method study," Coaching: An International Journal of Theory, Practice and Research, 2012.

[18] C. van Nieuwerburgh, C. Zacharia, E. Luckham, G. Prebble, and L. Browne, Coaching Students in a Secondary School, 2012.

[19] W. Madden, L. S. Green, and A. M. Grant, "A pilot study evaluating strengths-based coaching for primary school students: Enhancing engagement and hope," International Coaching Psychology Review, vol. 7, no. 1, pp. 71-83, 2011.

[20] H. Vlach and S. Calver. (2008). The Effects of Observation Coaching on Children's Graphic Representations. [Online]. Available: http://ecrp.uiuc.edu/v10n1/vlach.html

[21] M. E. Dingman, The effects of executive coaching on job-related attitudes, Regent University, 2004

[22] J. S. Hattie, Visible Learning: ASynthesis of over 800 Meta-Analyses Relating to Achievement, New York: Routledge, pp.38, 2009.

[23] A. S. Bryk and B. Schneider, Trust in Schools: A Core Resource for Improvement, Russell Sage Foundation, New York, 2002.

[24] T. Bergen, A. Engelen, and K. Derksen, "What is going on during the coaching conference between coach and teacher?" Paper presented at the American Educational Research Association, New Orleans, April 24-28th, 2000

[25] G. Nuthall, The Hidden Lives of Learners, NZCER Press, 2007.

[26] H. S. Timperley. (2001). Mentoring conversations designed to promote student teacher learning. Asia-Pacific Journal of Teacher Education. [Online]. 29(2). pp. 111-123. Available: http://instep.net.nz/Coaching

[27] U. Connor and K. Asenavage, "Peer response groups in ESL writing classes: How much impact on revision?" Journal of Second Language Writing, vol. 3, pp. 257-276, Thousand Oaks, CA: Corwin Press, 1994
[28] J. M. Chan, R. Lang, M. Rispoli, M. O’Reilly, J. Sigafoos, and H. Cole, "Use of peer-mediated interventions in the treatment of autism spectrum disorders: A systematic review," Research in Autism Spectrum Disorders, vol. 3, pp. 876-889, 2009.

[29] R. Boyatzis, Transforming Qualitative Information: Thematic analysis andCode Development, Thousand Oaks, CA: Sage, 1998.

[30] J. Passmore, Excellence in coaching: The industry guide, (ed.) $2^{\text {nd }} e d$., London: J. A. Smith \& M. Osborn, 2010.

[31] P. Hawkins and N. Smith, Coaching, Mentoring and Organizational Consultancy: Supervision and Development, Maidenhead: Open University, 2009.

[32] E. D. Haan and Y. Burger, Coaching with Colleagues: An Action Guide for One-To-One Learning, Basingstoke: Palgrave Macmillan, 2005.

[33] B. T. Crews and K. Wilkinson, "Students' perceived preference for visual and auditory assessment with e-handwritten feedback," Business Communication Quarterly, vol. 73, issue 4, pp. 399, 2010.

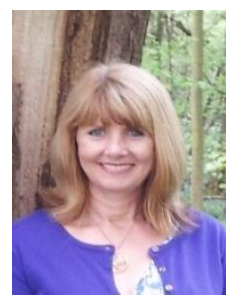

Linda Dorrington has worked for many years in the field of education and psychology at a senior leadership level. She is a trained teacher, counsellor and psychotherapist and has recently completed an MSc in Coaching Psychology with the University of East London. Linda is an Achievement Coach for the independent charity Achievement for All working with several different schools. She is also a Special Educational Needs Consultant. Linda is passionate about coaching and its 'solution-focussed'approach to resolving problems.

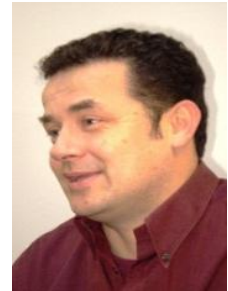

Christian van Nieuwerburgh is a well-respected executive coach, internationally recognised academic and sought-after consultant. Seen as an internationa authority in the field of coaching, he has been invited to speak at conferences in the US, the UK, Europe, Australia and the Middle East. He regularly presents on the topics of coaching, motivation, mental toughness and leadership. 